lymphocytes. The restoration of fetal haemoglobin levels to normal strongly suggests, however, that considerable clones of normal erythrocyte precursors exist. MLR performed between donor and recipient 18 weeks after the graft showed no significant transformation, but the recipient's lymphocyte function was still considerably depressed at that time (see table). Although engraftment has probably occurred, there have been reports of haemopoietic reconstitution in aplastic anaemia after immunosuppression without engraftment. ${ }^{11}$

Immunosuppression was not started until the patient was effectively decontaminated. The Vickers-Trexler isolator and ready provision of blood products from leukaphoresis and the blood transfusion service were essential prerequisites to the procedure. We hoped that the use of frozen stored red cells would diminish the risk of HLA sensitisation from multiple transfusions. As a precaution against graft rejection, the extended procarbazine, ATG, and cyclophosphamide suppressive regimen was used because it may permit marrow engraftment in sensitised individuals where cyclophosphamide alone fails. ${ }^{12}$ The gastrointestinal and bladder complications due to this regimen were considerable, however, and contributed to the severe cachexia that occurred after the graft.

Impaired resistance to Candida 21 weeks after the graft was a cellular defect. This may have been a consequence of the varicella infection. Staphylococcal killing, assessed one week later, was normal, but this difference might have reflected inadequate programming of the granulocytes by relatively incompetent $\mathrm{T}$ lymphocytes. The nitroblue tetrazolium test gave a normal result 23 weeks after the graft.

Bone marrow grafting should certainly be considered in Fanconi's anaemia when patients show deterioration and are resistant to medical treatment.

We should like to thank Sister J Meyers and her nurses, Westminster Children's Hospital; Dr I M Anderson for help and en- couragement; Lt-Col J G Winwick and W O I Bushrod of the Army Blood Supply Depot, Aldershot, for supplies of frozen red cells; Dr J Kersey for supplying ATG; Miss M O'Riordan, MRC cytogenics Unit, Edinburgh, for performing the chromosome studies; and Mr P C Trexler and his assistants at the Royal Veterinary College for help in running the isolator. We are grateful to the Andrew Bostic Fund, which paid most of the isolator costs and to the Anthony Nolan Fund, which completely supports the tissue typing laboratory. Without the joint assistance of these funds, this work would have been impossible. Miss Susan English typed the manuscript.

ADDENDUM-Since this report was written another two-way mixed lymphocyte reaction between the patient and the donor has been performed ( 11 months after the graft). There was no evidence that the patient had become sensitised to the donor. The T-lymphocyte function of the recipient has remained normal, as have his haematological values.

\section{References}

1 Storb, R, et al, Blood, 1974, 44, 1.

2 Dooren, L, Paper presented at IIIrd International Meeting of Experimental Haematologists, Houston, USA, 1974. (Abstracts p 50.)

${ }^{3}$ Yamamura, M, Nikbin, B, and Hobbs, J R, fournal of Immunological Methods, 1976, 10, 367.

${ }^{4}$ Yamamura, M, Clinical and Experimental Immunology, 1973, 14, 457.

5 Dondal, M, Holm, G, and Wigzel, H, fournal of Experimental Medicine, 1972, 136, 207.

${ }^{6}$ McLaughlin, H, et al, British fournal of Haematology, 1973, 25, 7

7 Storb, R, et al, Blood, 1974, 43, 157.

${ }^{8}$ Humble, J G, and Barrett, A J, Proceedings of the Royal Society of Medicine, 1975, 68, 580 .

9 Beard, M E J, et al, Quarterly fournal of Medicine, 1973, 42, 403.

${ }^{10}$ Trexler, P C, Spiers, A S D, and Gaya, H, British Medical fournal, 1975, 4, 549.

1 Speck, B, et al, Experimental Haematology, 1976, 4, 131.

12 Kersey, J, et al, Transplantation, 1975, 15, 92.

\title{
Why hypertensive patients vary in their response to oral debrisoquine
}

\footnotetext{
Section of Therapeutics, Academic Division of Medicine, University of Sheffield, and Sheffield Hypertension Clinic, Royal Infirmary, Sheffield S6 3DA

J H SILAS, MB, MRCP, research assistant

M S LENNARD, MSC, research assistant

G T TUCKER, BPHARM, PHD, lecturer

A J SMITH, DM, FRCP, consultant physician and associate in medicine

Department of Drug Metabolism, Roche Products Limited, Welwyn Garden City, Hertfordshire AL7 3AY

S L MALCOLM, BSC, research biochemist

T R MARTEN, BSC, DPHIL, senior research biochemist
}

urinary excretion and pre-dose plasma concentration of unchanged drug but an inverse correlation between daily urinary excretion of debrisoquine and its 4hydroxy metabolite $(r=-0.86)$, suggesting that a low recovery of debrisoquine occurs because of extensive metabolism.

There was a significant correlation between the fall in standing systolic blood pressure and the mean daily urinary excretion $(r=+0.82)$ and pre-dose plasma concentration ( $r=+0 \cdot 82)$ of unchanged debrisoquine. In contrast, there was a significant inverse correlation between the urinary recovery of the metabolite and the fall in blood pressure $(r=-0 \cdot 82)$.

The availability of debrisoquine is the major determinant of response to this drug. In the absence of side effects a poor response may be an indication to increase the daily dose rather than add another hypotensive agent.

\section{Introduction}

Variation in response to antihypertensive agents may be due to differences in their availability and concentration at the site of action, in their uptake into this site, in receptor "sensitivity," or 
in mechanism(s) responsible for the rise in blood pressure. The last has received much attention recently, partly because of a greater understanding of the different factors that may cause hypertension. For example, a response to drugs that act on the sympathetic nervous system may be related to the pretreatment plasma renin activity ${ }^{1}$ or to the plasma catecholamine concentration of the patient, ${ }^{2}$ although there are conflicting views. ${ }^{3}{ }^{4}$

The daily dose of debrisoquine by mouth needed to control the blood pressure of 120 patients attending the Sheffield Hypertension Clinic ranges from 10 to $360 \mathrm{mg}$. As most of these patients presented with moderate or severe hypertension, differences in pretreatment blood pressure cannot explain the wide range of dose required. A correlation between the fall in blood pressure in healthy volunteers and the amount of unchanged debrisoquine recovered in their urine was shown recently. "We have examined the relation between the fall in blood pressure and the plasma concentration and urinary excretion of debrisoquine and 4-hydroxydebrisoquine (a principal metabolite) in a group of patients with benign hypertension. These patients differed in salt intake, plasma renin activity, and urinary catecholamine excretion and there was no demonstrable primary cause of their hypertension.

\section{Patients and methods}

Thirteen patients with moderate or severe benign essential hypertension were studied after primary causes of their hypertension had been excluded (see table). They had received no antihypertensive treatment for at least three weeks before the study. On a normal ward diet plasma renin activity was $0 \cdot 13-1 \cdot 74$ (mean $0 \cdot 71 \pm$ SD $0 \cdot 49)$ pmol angiotensin $\mathrm{I} / \mathrm{ml} / \mathrm{h}(0 \cdot 18-2 \cdot 48($ mean $1.02 \pm 0.70) \mathrm{ng} / \mathrm{ml} / \mathrm{h})$ and 24 -hour urinary noradrenaline excretion $81 \cdot 1-439 \cdot 3$ (mean $198 \cdot 9 \pm 93 \cdot 1$ ) nmol $(13 \cdot 7-74 \cdot 2$ (mean $33 \cdot 6 \pm 17 \cdot 9) \mu \mathrm{g}$ ).

Blood pressure was measured with the patients lying (10 minutes) and standing (one minute) on seven occasions over two days at identical times of day by the same observer using a random zero sphygmomanometer (Hawkesley). Mean blood pressure was calculated from the diastolic blood pressure (phase IV) plus one-third pulse pressure.

Biochemical analyses-Urinary debrisoquine (D) and 4-hydroxydebrisoquine (HD) were estimated by gas-liquid chromatography with flame ionisation detection ${ }^{6}$ (coefficient of variation $4 \%$ ). Plasma samples were examined for these compounds by mass fragmentography $^{7}$ (coefficients of variation: D 5\%, HD 9\%). Plasma renin activity was measured ${ }^{8}$ at 10 am on blood samples withdrawn after an overnight fast and two hours of recumbency. Urinary noradrenaline was estimated ${ }^{9}$ from a single 24 -hour urine collection made the second day after admission.

Protocols-Patients were admitted to an investigation ward for 48 hours before treatment began and again when they had been receiving $\mathrm{D}$ alone for two to three months on a 12-hourly basis and had been on the same dose for at least three weeks. For three days before readmission dosing was carried out at exactly the same time as on the ward; food was not taken for two hours before and after medication. Compliance was assessed by tablet counts and was better than $95 \%$ in every patient. During the second admission two 24-hour urine collections were made and venous blood was taken just before and two hours after the morning dose for the estimation of D and HD. This had been shown to provide trough and peak concentrations for both compounds (unpublished data). Twelve patients were studied on a daily dose of $40 \mathrm{mg}$ but four were studied on more than one dose (see table). The blood pressure data from one patient (case 6) were excluded, as they were incomplete.

\section{Results}

There was a large variation in the mean daily urinary recovery of $\mathrm{D}$ and $\mathrm{HD}$ in the 12 patients given $40 \mathrm{mg}$ daily (table). The recovery of D varied from $8.6 \%$ to $80.2 \%$ of the dose (mean $33.9 \pm$ SD $20.1 \%$ ); that of HD varied from nil to $29.7 \%$ (mean $13.6 \pm 8.0 \%$ ), and it was not detectable in two patients. Total recovery varied from $27.4 \%$ to $80.2 \%$ (mean $(47.5 \pm 14.3 \%$ ), and the median $\mathrm{D}: \mathrm{HD}$ ratio was 2.69 . The proportion of the dose recovered as $\mathrm{D}$ was inversely related to that recovered as the hydroxymetabolite (fig 1).

There was also a large variation in the mean plasma concentration of $\mathrm{D}$ and $\mathrm{HD}$ in the 12 patients receiving a daily dose of $40 \mathrm{mg}$. Plasma

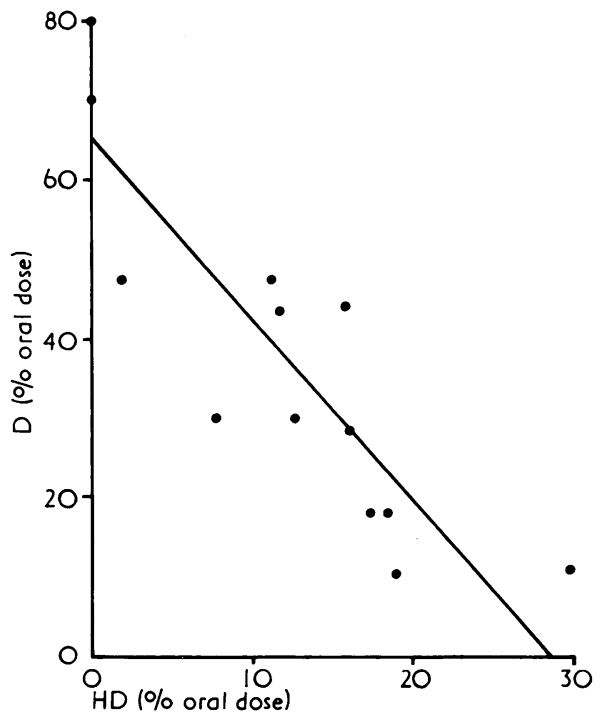

FIG 1-Correlation between mean daily urinary recovery of 4-hydroxydebrisoquine (HD) and unchanged debrisoquine (D) in 13 hypertensive patients $(r=-0.86 ; P<0.001)$

Details of patients, fall in blood pressure, and urinary recovery and plasma concentrations of debrisoquine and 4-hydroxydebrisoquine

\begin{tabular}{|c|c|c|c|c|c|c|c|c|c|c|}
\hline \multirow[t]{2}{*}{ Case No } & & \multirow{2}{*}{$\begin{array}{l}\text { Daily dose* } \\
(\mathrm{mg})\end{array}$} & \multirow{2}{*}{$\begin{array}{l}\text { Initial BP } \\
(\mathrm{mm} \mathrm{Hg})\end{array}$} & \multicolumn{3}{|c|}{ Fall in standing $\mathrm{BP}(\mathrm{mm} \mathrm{Hg})$} & \multicolumn{2}{|c|}{ Mean 24-h urinary recovery } & \multicolumn{2}{|c|}{$\begin{array}{c}\text { Pre-dose plasma } \\
\text { concentration }(\mathrm{ng} / \mathrm{ml})\end{array}$} \\
\hline & & & & Systolic & Diastolic & Mean & $\mathrm{D}$ & HD & $\mathrm{D}$ & HD \\
\hline $\begin{array}{c}1 \\
2 \\
3 \\
4 \\
5 \\
6 \ddagger \\
7 \\
8 \\
9 \\
10 \\
\\
11 \\
12 \\
13\end{array}$ & \{ & $\begin{array}{r}40 \\
40 \\
40 \\
40 \\
40 \\
80 \\
40 \\
40 \\
40 \\
20 \\
40 \\
80 \\
40 \\
80 \\
120 \\
40 \\
40 \\
80\end{array}$ & $\begin{array}{l}180 / 116 \\
184 / 120 \\
183 / 111 \\
168 / 111 \\
168 / 110 \\
180 / 132 \\
221 / 121 \\
173 / 119 \\
194: 135 \\
188: 140 \\
176 / 114 \\
187: 140\end{array}$ & $\begin{array}{r}25 \cdot 1 \\
44.4 \\
5.7 \\
13.7 \\
0.3 \\
21 \cdot 2 \\
24.0 \\
34.4 \\
6.9 \\
36.9 \\
67.4 \\
5.1 \\
10 \cdot 0 \\
38.8 \\
27.1 \\
7.5 \\
48.0\end{array}$ & $\begin{array}{c}34.8 \\
27.6 \\
0.5 \\
11.6 \\
+5.0^{+} \\
13.6 \\
22.6 \\
21.8 \\
14.9 \\
31.4 \\
53.1 \\
8.6 \\
25.1 \\
36.0 \\
16.6 \\
12.8 \\
39.4\end{array}$ & $\begin{array}{c}31.0 \\
33.4 \\
2.0 \\
12.4 \\
+1.8+ \\
18.2 \\
23.0 \\
28.2 \\
11.1 \\
33.1 \\
58.2 \\
7.3 \\
20.1 \\
36.3 \\
19.9 \\
10.4 \\
41.3\end{array}$ & 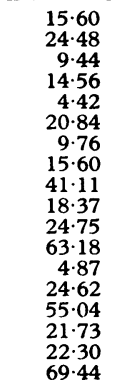 & $\begin{array}{c}6.57 \\
1.13 \\
8.97 \\
8.38 \\
9.64 \\
20.94 \\
9.47 \\
3.99 \\
0 \\
0 \\
5.96 \\
12.66 \\
15.24 \\
23.67 \\
30.45 \\
6.03 \\
8.32 \\
8.08\end{array}$ & $\begin{array}{r}65 \\
68 \\
19 \\
26 \\
9 \\
45 \\
21 \\
35 \\
75 \\
41 \\
62 \\
113 \\
25 \\
71 \\
75 \\
43 \\
60 \\
122\end{array}$ & $\begin{array}{r}23 \\
0 \\
10 \\
10 \\
9 \\
40 \\
10 \\
7 \\
0 \\
0 \\
11 \\
21 \\
18 \\
28 \\
24 \\
8 \\
14 \\
14\end{array}$ \\
\hline
\end{tabular}

*A 10-mg debrisoquine tablet contains $10 \mathrm{mg}$ debrisoquine base but $12.8 \mathrm{mg}$ hemisulphate. 
concentrations of $\mathrm{D}$ just before the morning dose ranged from 9 to 75 (mean $42 \pm 22.7) \mathrm{ng} / \mathrm{ml}$ and two hours after the dose 15-182 (mean $76 \pm 53.5) \mathrm{ng} / \mathrm{ml}$. Corresponding values for HD were 0-23 (mean $10 \pm 6 \cdot 5) \mathrm{ng} / \mathrm{ml}$ and $0-47$ (mean $22 \pm 15 \cdot 4) \mathrm{ng} / \mathrm{ml}$.

In 11 patients receiving $40 \mathrm{mg}$ daily the fall in standing systolic blood pressure varied from 0.3 to 44.4 (mean $20.4 \pm 14.8$ ) $\mathrm{mm} \mathrm{Hg}$, and the pressure was significantly different from pretreatment values in nine of these (one-tailed $t$ test). The fall in supine blood pressure was less pronounced $(2 \cdot 9-32.8$ (mean $15.8 \pm 10.3) \mathrm{mm} \mathrm{Hg}$ ), and the pressure was significantly different from pretreatment values in only five. A significant positive linear correlation was found between the fall in standing systolic, diastolic, or mean blood pressure and mean daily urinary recovery of unchanged $\mathrm{D}$ in patients receiving the same dose (systolic blood pressure: $\mathrm{r}=+0.75 ; \mathrm{P}<0.01 ; \mathrm{n}=11$ ). This correlation was improved by including data from all patients on a daily dose of $20-120 \mathrm{mg}$ (fig 2).

In contrast, an inverse correlation was noted between the mean daily urinary recovery of $\mathrm{HD}$ and the fall in standing systolic, diastolic, or mean blood pressure but was observed only in patients receiving the same dose-that is, $40 \mathrm{mg}$ daily (fig 3). This is explained by the fact that larger doses result in an increase in metabolite but a further reduction in blood pressure. A significant positive correlation between total urinary recovery $(\mathrm{D}+$ metabolite) and fall

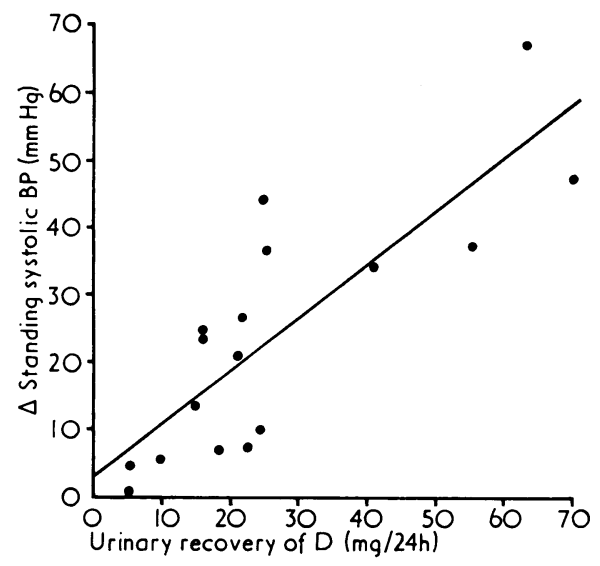

FIG 2-Correlation between mean daily urinary recovery of debrisoquine (D) and fall in standing systolic blood pressure $(r=+0.82 ; \mathrm{P}<0.001$; $\mathrm{n}=17$ ).

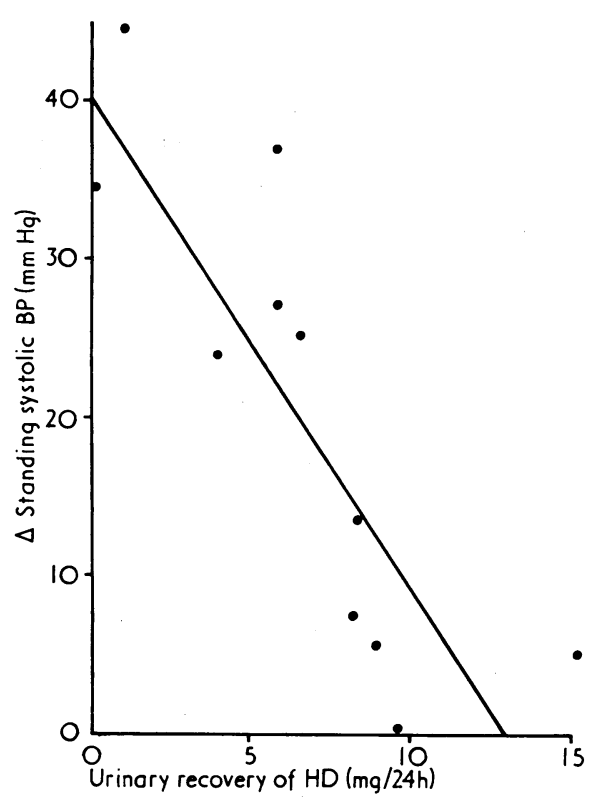

FIG 3-Correlation between mean daily urinary recovery of 4-hydroxydebrisoquine (HD) and fall in standing systolic blood pressure in 11 patients receiving $40 \mathrm{mg}$ debrisoquine daily $(r=-0.82 ; P<0.01)$. in standing blood pressure was observed, but this was not as great as that relating unchanged $\mathrm{D}$ only to the fall in blood pressure (systolic: $\mathrm{r}=+0.73 ; \mathrm{P}<0.001 ; \mathrm{n}=17$ ).

Plasma data support the urinary findings. On the same dose of D there was a positive correlation between pre-dose plasma $\mathrm{D}$ concentration and the fall in standing systolic, diastolic, or mean blood pressure (systolic blood pressure: $\mathrm{r}=+0.79 ; \mathrm{P}<0.001 ; \mathrm{n}=11$ ). The correlation between plasma $D$ concentrations in venous samples and systolic blood pressure two hours after the dose was $+0.62(\mathbf{P}<0.05)$. These correlations were similar on inclusion of data from all patients on a daily dose of 20-120 mg (fig 4).

An inverse correlation between plasma HD concentration and the fall in standing systolic blood pressure on a $40-\mathrm{mg}$ dose was noted but it reached significance only for peak plasma values (systolic blood pressure: $r=-0.66 ; \mathrm{P}<0.05 ; \mathrm{n}=11$ ).

There was no significant relation between the urinary recovery or plasma concentration of $\mathrm{D}$ or $\mathrm{HD}$ and the fall in supine blood pressure.

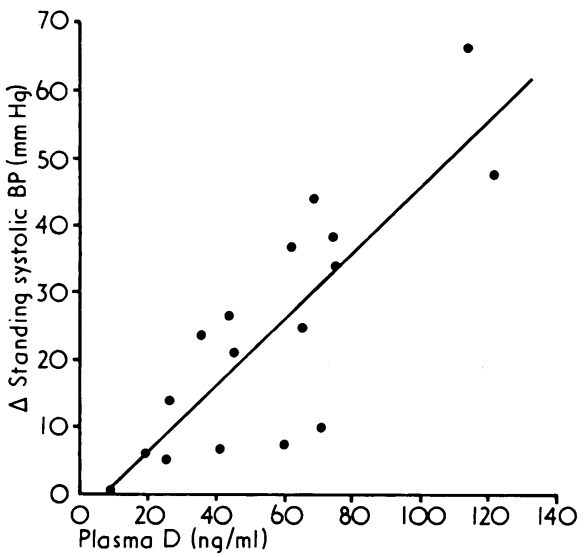

FIG 4-Correlation between mean daily pre-dose plasma debrisoquine (D) concentration and fall in standing systolic blood pressure $(\mathrm{r}=+0.82$;
$\mathrm{P}<0.001 ; \mathrm{n}=17)$.

\section{Discussion}

A ninefold variation was observed in pre-dose plasma $\mathrm{D}$ concentration in compliant patients receiving the same dose. Over $75^{\circ}{ }_{0}$ of the drug is absorbed ${ }^{10} 11$ but several metabolites have been identified. ${ }^{12} 13$ The inverse correlation between the recovery of the 4-hydroxy metabolite and that of the parent compound suggests that metabolism and not absorption is the major determinant of the availability of $\mathrm{D}$.

Interpatient variability in response to a given dose of $\mathrm{D}$ by mouth was confirmed. Most of this variation can be related to the availability of the unchanged drug, which appears to be responsible for the fall in blood pressure. Extensive metabolism of $\mathrm{D}$ was associated with a poor response and, in comparison to the parent compound, the hypotensive effect of HD was insignificant.

By implication, the other factors influencing the response to $\mathrm{D}$ appear to be less important than the plasma concentration of the active agent. Our patients were heterogeneous with respect to renin activity and catecholamine output and no attempt was made to control salt intake. Plasma volume influences, standing blood pressure, ${ }^{14}$ and concomitant salt restriction or diuretic administration or both may improve the correlation between plasma D concentration and the fall in blood pressure still further. These patients, however, received no other drugs.

A mechanism that may be responsible for resistance to treatment with postganglionic sympathetic blocking agents is increased sensitivity to circulating catecholamines. ${ }^{15}$ From our data it seems unlikely that receptor sensitivity is a major determinant of the effect of $\mathrm{D}$ in patients controlled on a daily dose of $120 \mathrm{mg}$ or less over a short period. A few of our patients, however, need much larger doses, and in these, pharmacodynamic factors may be important. Furthermore, during 
prolonged treatment secondary changes such as fluid retention may necessitate increments in the daily dose in resistant cases.

It has been suggested that a combination of hypotensive agents given in low dose is a useful way to reduce high blood pressure. ${ }^{16}$ Nevertheless, the response to D was related to its plasma concentration. A poor response was associated with extensive metabolism of the drug and was overcome by increasing the dose rather than by adding other hypotensive agents to the therapeutic regimen. This is important since compliance may fall as a result of using several drugs. ${ }^{17}$

Dr J H Silas is in receipt of a grant from Roche Products Limited, Welwyn Garden City, Hertfordshire.

\section{References}

${ }^{1}$ Buhler, F R, et al, New England fournal of Medicine, 1972, 278, 1209.
2 Louis, W J, Doyle, A E, and Anavekar, S, New England fournal of Medicine, 1973, 288, 599.

3 Sjoerdsma, A, Circulation Research, 1967, 21, suppl No 3, p 119.

${ }^{4}$ Morgan, T D, et al, British fournal of Clinical Pharmacology, 1975, 2, 159.

5 Angelo, M, et al, British fournal of Pharmacology, 1975, 55, 264.

${ }^{6}$ Lennard, M S, et al, fournal of Chromatography, 1977, 133, 161.

7 Malcolm, S L, and Marten, T R, Analytical Chemistry, 1976, 48, 807.

8 Cohen, E L, fournal of Laboratory and Clinical Medicine, 1971, 77, 1205

9 Townshend, M M, and Smith, A J, Clinical Science and Molecular Medicine, 1973, 44, 253.

${ }_{10}$ Angelo, M, et al, Biochemical Society Transactions, 1976, 4, 704.

${ }_{11}$ Kitchen, A H, and Turner, R W D, British Medical fournal, 1966, 2, 728.

12 Allen, J G, et al, Drug Metabolism and Disposition, 1975, 3, 332.

13 Allen, J G, Brown, A N, and Marten, T R, Xenobiotica, 1976, 6, 405.

14 Dunstan, H P, Tarazi, R C, and Bravo, E L, New England fournal of Medicine, 1972, 286, 861 .

15 Sandler, G, Leishman, A W D, and Humberstone, P J, Circulation, 1968, 38, 542.

16 Petrie, J C, et al, British Medical fournal, 1976, 3, 137.

17 Weintraub, M, Au, W, and Lasagna, L, fournal of the American Medical Association, 1973, 224, 481.

\title{
Recurrent breast cancer treated with the antioestrogen tamoxifen: correlation between hormonal changes and clinical course
}

\author{
K J WILLIS, D R LONDON, H W C WARD, W R BUTT, S S LYNCH, B T RUDD
}

British Medical fournal, 1977, 1, 425-428

\section{Summary}

Forty-five post-menopausal women with recurrent breast cancer were treated with the antioestrogen, tamoxifen, $20 \mathrm{mg}$ twice daily. Clinical assessment after 12 weeks indicated that $18(40 \%)$ showed some remission. Gonadotrophins were suppressed within two weeks to relatively constant concentrations within the post-menopausal range, responses to luteinising hormone-releasing hormone (LH-RH) did not change, and androgen concentrations remained within the normal range in all patients. Oestradiol concentrations rose steadily only in women in whom treatment failed. Serum prolactin concentrations were raised in 18 out of the $44(41 \%)$ patients in whom they were measured; 13 of these did not respond to treatment. Treatment did not change the average prolactin concentration when this was within the normal range, but it significantly reduced prolactin concentrations in hyperprolactinaemic patients-within two

\section{Queen Elizabeth Hospital, Birmingham B15 2TH}

K J WILLIS, MB, MRCP, research fellow (present address: Imperial Cancer Research Fund, Department of Medical Oncology, St Bartholomew's Hospital, London)

D R LONDON, DM, FRCP, consultant physician

$\mathrm{H}$ W C WARD, FRCR, MRCP, consultant radiotherapist (now Professor and Chief, Department of Radiation Oncology, South Western Medical School, University of Texas, Dallas)

Department of Clinical Endocrinology, Birmingham and Midland Hospital for Women, Birmingham B11 4HL.

W R BUTT, DSC, FRIC, professor of endocrinology

S S LYNCH, PHD, principal biochemist

B T RUDD, PHD, principal biochemist weeks $(P<0.01)$ in those who responded well and by six weeks $(P<0.05)$ in those who showed no remission. Among patients with normal prolactin values the release of prolactin after thyrotrophin-releasing hormone was significantly greater in those with no remission than in those who responded to tamoxifen. Responses in those with hyperprolactinaemia were reduced to about half the control values, and again this change occurred faster in those who were successfully treated. Patients therefore seem to have a better chance of responding to antioestrogen treatment if prolactin secretion is low.

\section{Introduction}

Breast cancer is the commonest malignancy to affect European and American women, and considerable efforts have been made to understand its pathogenesis and improve treatment. Hormonal manipulation has been tried for palliating inoperable disease. The endocrine glands have been surgically ablated, ${ }^{1-3}$ and corticosteroids have been administered. ${ }^{4}$ Both methods may produce remissions in about a third of patients ${ }^{5-7}$ but there is no reliable way of predicting who will respond. Bulbrook, ${ }^{8}$ for example, derived a discriminant function but its predictive value is affected by many factors, including age, obesity, menopausal status, and drugs. ${ }^{910}$

Specific oestrogen receptors have been recognised in some breast tumours. ${ }^{112}$ Since antioestrogens ${ }^{13}$ compete for binding with oestrogen at target sites ${ }^{14}$ a trial of such compounds in the treatment of breast cancer is indicated. The antioestrogen tamoxifen (Nolvadex) ${ }^{15}$ has been well tolerated by patients with inoperable breast cancer and has produced some clinical improvement. ${ }^{16} 17$

There have been few studies of the hormonal changes produced by tamoxifen in patients with breast cancer. ${ }^{18} 19 \mathrm{We}$ determined its effects on pituitary and steroid hormones in postmenopausal patients with recurrent breast cancer and 